\title{
REDUCTION OF NON-VALUE ADDED ACTIVITIES IN AN APPAREL MANUFACTURING THROUGH VALUE STREAM MAPPING (VSM)
}

\author{
S Appaiah ${ }^{1}$, C.S.Chethan Kumar ${ }^{2}$, Varun Bhatt $^{3}$ \\ ${ }^{1}$ Associate Professor, Department of IEM, MSRIT \\ ${ }^{2}$ Associate Professor, Department of IEM, MSRIT \\ ${ }^{3}$ PG Student, Department of IEM, MSRIT, Bengaluru
}

\section{Abstract}

This paper discusses the problems with the Current State Map (CSM) were identified, by highlighting non-value added activities, The existing system is investigated for lead time problems and suitable remedial measures were implemented through VSM. The lean concepts and techniques are implemented in a garment unit. The outcome is that the the complete lead time is once decreased from 51 days to 43 days. The WIP at every work station has also been decreased.

Keywords: Lean Manufacturing, Lead Time, Non-value added activity, Value added activity, Value Stream Mapping, WIP, Wastage.

\section{INTRODUCTION}

Medium scale garment manufacturing industry for the shorts and pants, as a way to critically analyze the manufacturer's manufacturing method and subsequently to establish the waste streams. Industry is operating under the "make to order" technique of lean manufacturing, which means it does now not hold a giant stock of completed components and best creates a precise number of production depends on the customer demand. Whereas the fundamental objective was to scale down the current lead time by way of at least $50 \%$, In order to achieve that goal, required to document the present state of the creation method, future state map was once developed with the objective of making improvements to the productivity With the construction of a preliminary and final state VSM, we were able to attract conclusions founded on the research and information collected.

\section{LITERATURE REVIEW}

A headlong rush to decrease the lead time by becoming lean has created urgency for researchers and practitioners to apply new tools and strategies for dictating wastages. This research addresses the application of value stream mapping in garments industry to implement lean manufacturing. Value stream mapping is different than conventional recording approaches as it helps in the visualization of Material Flow, Information Flow, cycle times and utilization of resources. Assurance of effective integration and communication, lean systems may also be accomplished with higher efficiency [1].

Chethan Kumar C.S, N.V.R Naidu, illustrated the importance of using the lean principles to eliminate non value added wastes in garment industry [2]. The redesigned process is more effective and efficient than the previous one [4]. The moderate to large manufacturing industry depends on a long and integrated supply chain, consisting of inbound logistic, conversion process and outbound logistic. Integrated line balancing is minimization of cost for inbound and outbound logistic subsystems. The generic approach has been developed for linking the balancing of the line of production in the conversion area with the customers' rate of demand in the market and for configuring the related stock chambers [5].

In the paper of Dr.C.S. Chethan Kumar and Dr.N.V.R. Naidu [6] explains about the Lean manufacturing methods that are appropriate for a company will vary according to the company's maturity in lean manufacturing and the issues they are facing.

\subsection{Problem statement}

Based on the analysis of the existing system studies done, as the garment industry manufactures variety of readymade garments and exports the garments to other countries, but now a day the company plans to improve production rate with less wastages. Generally these wastes are overproduction, correction (rework), waiting and inventory of the manufacturing product .where the company ploy to increase the productivity of the industries alongside it tries to reduce the wastages of the manufacturing and lead time to manufacture the products.

\subsection{Objectives}

Henceforth the objective of this work is to make sense of by what method can lean manufacturing is used to accomplish the following:

- To reduce the defects in sewing section

- To identify the wastes in storage, cutting, sewing, finishing and packing department

- Identifying the areas where changes have been made to implement lean

- $\quad$ To reduce the lead time 


\section{METHODOLOGY}

1. Selection of Product Family

2. Current State Map

Step-1 Calculate Takt Time

Step-2 Understand customer demand

Step-3 Map the process flow

Step-4 Map the material flow

Step-5 Map the information flow

Step-6 Draw the Time line

3. Future State Map
Value stream mapping is drawn for the existing system by following the following procedures.

Steps to use the value stream mapping tool

Step 1: Identify the product or service to map.

Step 2: Draw the current value stream map.

Step 3: Assess the current value stream.

Step 4: Develop a Future State value stream map.

Step 5: Develop a plan to implement the desired state.

\section{VALUE STREAM MAPPING OF CURRENT}

\section{STATE (CSM)}
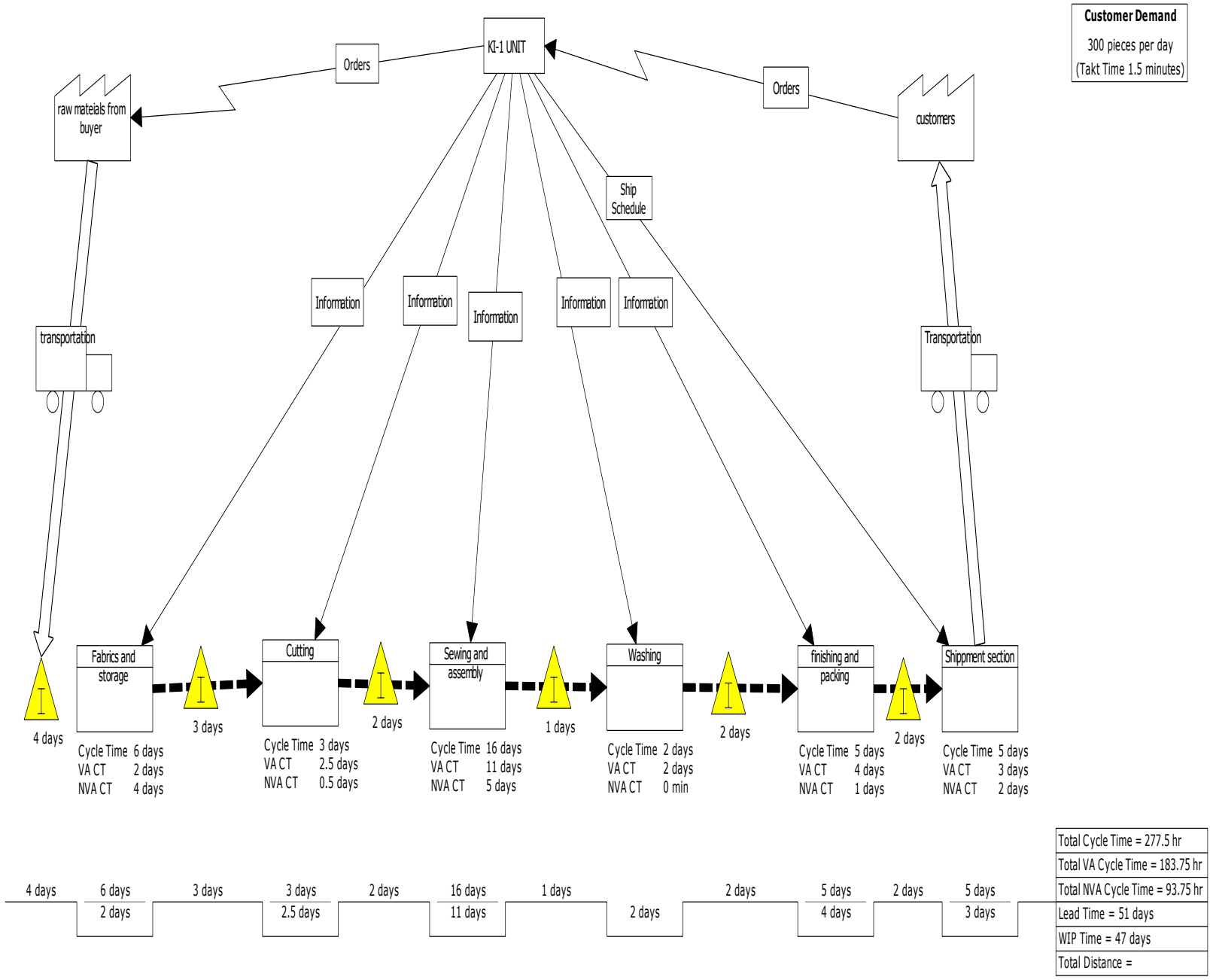

Fig.1: Value Stream Mapping of Current State

The outcomes from Future State Value Stream Map are as follows:

The Total Cycle Time $=277.5 \mathrm{hr}$

Value Added Cycle Time $=183.75 \mathrm{hr}$

Non Value Added Cycle Time $=94 \mathrm{hr}$

Lead Time $=51$ days
$\mathrm{WIP}=47$ day

\section{Disadvantages in the current scenario}

- More of in-process inventory.

- Excessive setup time 


\section{FUTURE STATE VALUE STREAM MAPPING (FSM)}

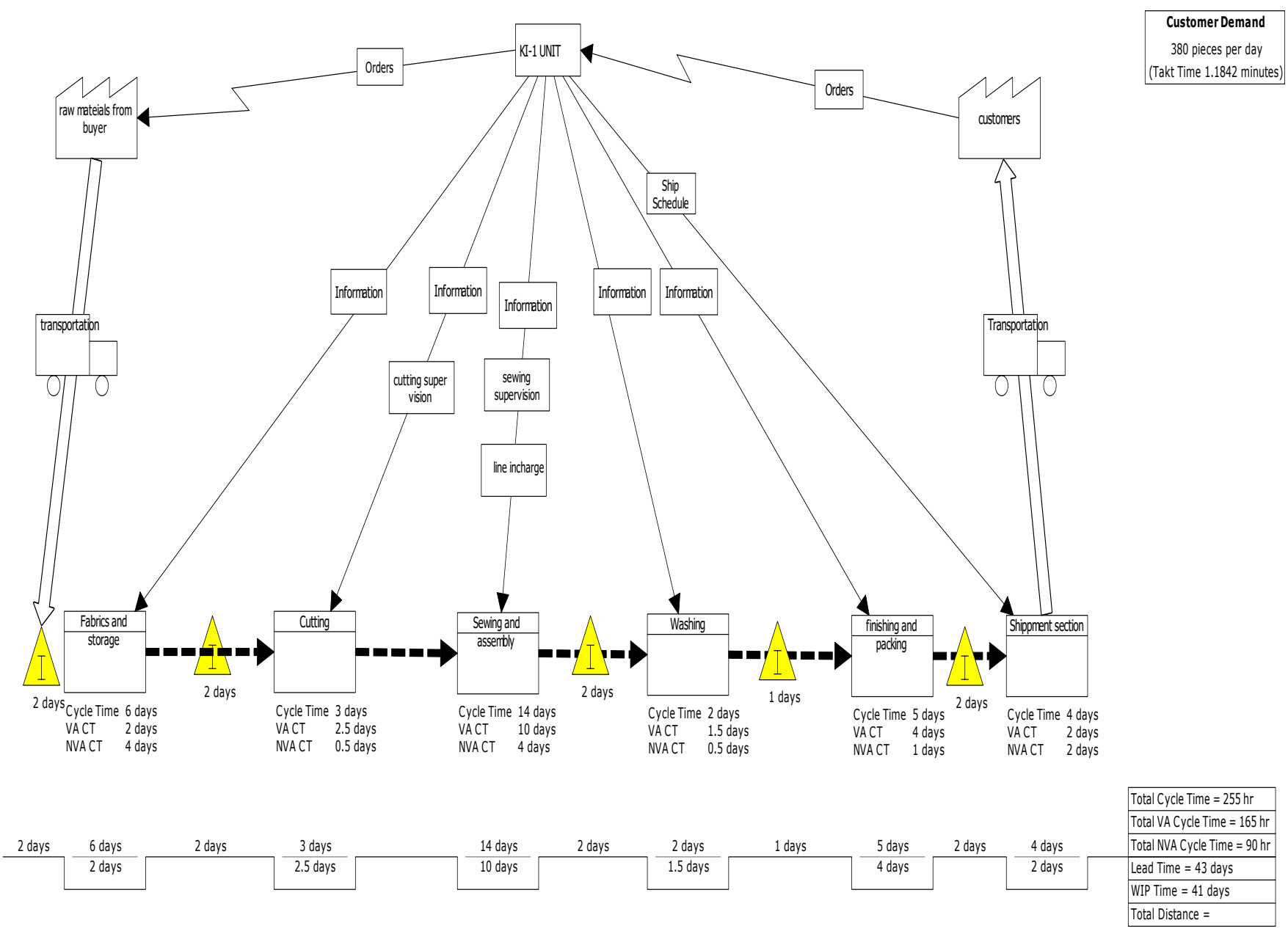

Fig.2: Future State Value Stream Mapping

The outcomes from Future State Value Stream Map are as follows:

The Total Cycle Time $=255 \mathrm{hr}$

Value Added Cycle Time $=165 \mathrm{hr}$

Non Value Added Cycle Time $=90 \mathrm{hr}$

Lead Time $=43$ days

WIP=41 day

Value stream mapping activities should be developed with specific implementation to plans This process is repeated for all value streams across the organization in order to achieve world class improvement results. The true value in value stream mapping is the creation of process improvement plans that can be implemented systematically across the company with sustainable results.

\section{CONCLUSION}

Lead time is diminished with the application of VSM. The result is that the lead time is reduced from 51 days to 43 days.

\section{REFERENCES}

[1]. Dilip Roy And Debdip Khan, (2010) "Integrated Model For Line Balancing With Workstation Inventory Management", International Journal Of Industrial Engineering Computations.

[2]. Chethan Kumar C S, Dr. N V R Naidu, Minimizing the eighth waste of lean- Absenteeism through Six sigma methodology, International journal for Quality Research, Vol. X No. X, pp.505-512, 2011.

[3]. EdrawSoft (2012). Value stream mapping software.Edraw Max, Retrieved February 20, 2012, from http://www.edrawsoft.com/Value-Added-Flow-Chart.php [4]. G. Sahitya Reddy, Harsha Lingareddy, K.Jagadeeshwa, "Value Stream Mapping In a Manufacturing Industry" International Journal of Advanced Engineering Technology. [5]. R.M. Belokar, Sandeep Singh Kharb, Vikas, 2012 "An Application Of Value Stream Mapping In Automobile Industry: A Case Study “, International Journal Of Innovative Technology and Exploring Engineering.

[6]. A Survey on Awareness of Lean Manufacturing Concepts in Indian Garment Manufacturing Industries by Dr.C.S. Chethan Kumar and Dr.N.V.R. Naidu, Page No. 783 [7]. Emil suciu, Mihal, Arvinte value stream mapping-A lean production methodology, 2011 